\title{
Conservative treatment for osteoid osteoma of the odontoid process of the axis: a case report
}

\author{
Jun Qiao, Feng Zhu, Zezhang Zhu, Zhen Liu, Bangping Qian and Yong Qiu*
}

\begin{abstract}
Background: Osteoid osteoma is a primary benign bone lesion, which constitutes about $10 \%$ of all primary benign bone tumors and $3 \%$ of all primary bone tumors. The spine is involved in $10 \%$ of the cases, and the lumbar spine is the most commonly affected whereas the tumor is rarely seen in the cervical spine. With regard to the osteoid osteoma being located at the odontoid process of the axis, limited cases have been reported in the literature.

Case presentation: An osteoid osteoma of the odontoid process of the axis was diagnosed by computed tomography in an 18-year-old male patient with a 3-month history of pain. The patient's parents refused surgery for fear of surgical risks and high expense. Considering the benign nature of osteoid osteoma, we prescribed celecoxib $200 \mathrm{mg}$ per day to the patient. With the treatment, the patient's pain was alleviated gradually and the range of motion of the cervical spine also recovered to normal. At the two-year phone follow-up, the patient was free of symptoms.
\end{abstract}

Conclusions: For this kind of benign tumor, conservative treatment plus close follow-up is applicable whereas surgery bears significant risks and a heavy economic burden.

Keywords: osteoid osteoma, axis, cervical, spine

\section{Background}

Osteoid osteoma, a primary benign bone lesion, was first defined by Jaffe in 1935 [1]. It pathologically features a highly vascularized nidus of connective tissue surrounded by sclerotic bone $[2,3]$. The nidus measures about $10 \mathrm{~mm}$ in diameter, and the size is the main distinguishing feature between it and osteoblastoma [4]. Osteoid osteoma constitutes about $10 \%$ of all primary benign bone tumors and $3 \%$ of all primary bone tumors [5]. Most of the cases occur in the first three decades and occurs two to three times more frequently in men than in women [6]. Predilection sites of the osteoid osteoma are long bones, especially those of the lower extremities. The spine is involved in $10 \%$ of the cases, and the lumbar spine is the most commonly affected whereas the tumor is rarely seen in cervical spine [7]. With regard to the osteoid osteoma being located at the odontoid process of the axis, limited cases have been reported in the literature $[8,9]$. Herein, we report an osteoid osteoma of the dens axis confirmed by radiographic examinations.

\footnotetext{
* Correspondence: scoliosis2002@sina.com

Spine Surgery, Drum Tower Hospital, Nanjing University Medical School, 321 Zhongshan Road, Nanjing 210008, China
}

\section{Case presentation}

An 18-year-old male patient had a history of neck pain of 3 months' duration, which was more severe at night. A physical examination revealed a remarkably reduced rotation to the right and mild kyphosis. A lateral cervical spine radiograph showed kyphosis of the cervical spine (Figure 1). A computed tomography (CT) scan revealed a lytic area involving the odontoid process of the axis with the partial ossification of the matrix and a sclerotic margin (Figure 2). By CT three-dimensional (3-D) reconstruction, the nidus was found at the conjunction of the odontoid process of the axis and the body of the axis (Figure 3).

From the patient's medical history and radiological and physical examination, we made a diagnosis of osteoid osteoma of the odontoid process of the axis. The patient's parents refused surgery for fear of surgical risks and high expense. Considering the benign nature of osteoid osteoma, we prescribed celecoxib $200 \mathrm{mg}$ per day to the patient. With the treatment, the patient's pain was alleviated gradually, and the range of motion of the cervical spine also recovered to normal. At the two-year phone follow-up, the patient was free of symptoms. However, he refused to go to our outpatient center for radiographic examinations. 


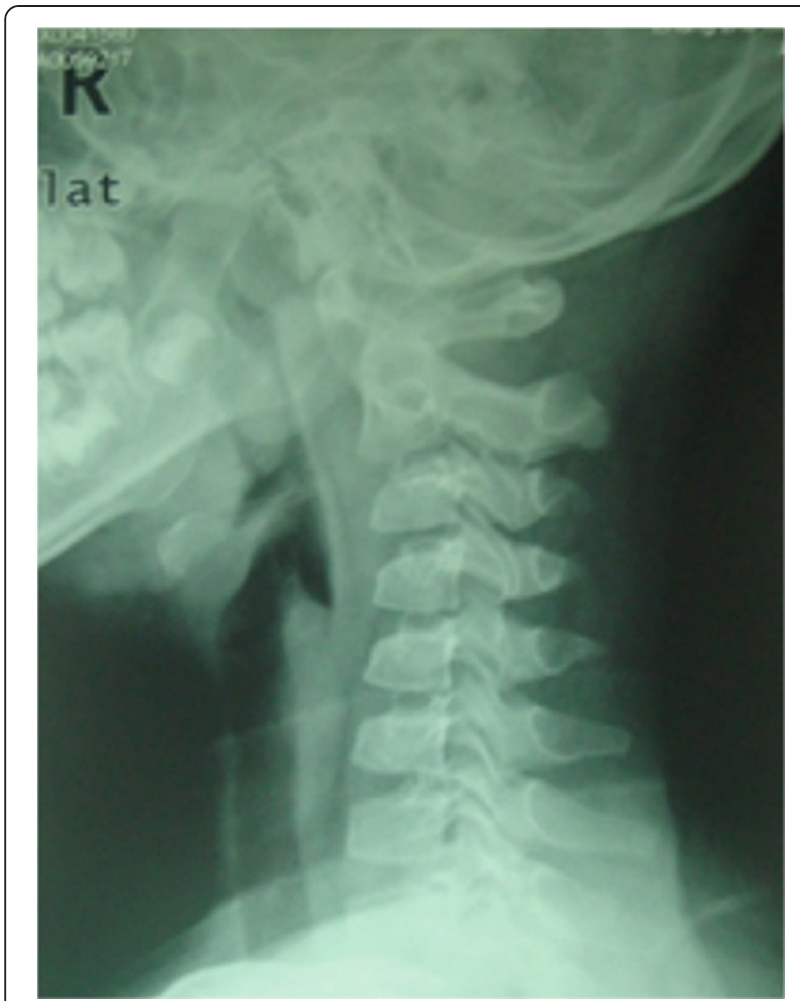

Figure 1 Lateral X-ray showing kyphosis of cervical spine.

\section{Discussion}

Osteoid osteoma is a benign tumor, for which the chief symptom is pain whereas other clinical symptoms are related to its location [10]. The pain is localized and may be aggravated with motion. At the same time, pain can also be alleviated with activity [11]. Localized pain is caused by the nerve fibers in the nidus. The production of prostaglandin may lead to an increase in vascular pressure, which may produce pain by stimulating afferent nerves around the nidus [12]. The pain is more severe at night and is relieved by non-steroidal anti-inflammatory drugs (NSAIDs) [13]. This feature could also be used as a diagnostic clue. Scoliosis is reported in $70 \%$ of the cases when the lesion involves the spine, and it is the most common cause of painful scoliosis in adolescents, especially when the lesion is located in lumbar or thoracic spine [14-16].

$\mathrm{CT}$ is recommended as the best diagnostic tool to define and localize the nidus, particularly when the nidus is located at the spine [13]. With CT scanning, we can optimally visualize the nidus with perifocal marginal sclerosis [17]. Conventional radiography is insufficient to visualize the lesion because of the complicated anatomy of the spine [17]. Magnetic resonance imaging (MRI) is not as accurate as $\mathrm{CT}$ in demonstrating the nidus because the nidus presents different signal intensity in different patients [18-20]. The increased signal intensity of the lesion on T2-weighted images or on enhanced T1weighted images was pathologically correlated with the degree of vascularity of the fibrovascular nidal stroma and the amount of osteoid substance within the nidus [21]. On the other hand, for detecting changes in soft tissue and bone marrow around the nidus, MRI is more sensitive than CT. These changes are due to bone marrow inflammation and edema $[18,21]$. In addition to CT and MRI, bone scintigraphy is also a sensitive diagnostic test.

Tumors that affect the axis vertebra are numerous and include osteoblastoma, eosinophilic granuloma, chondroma,

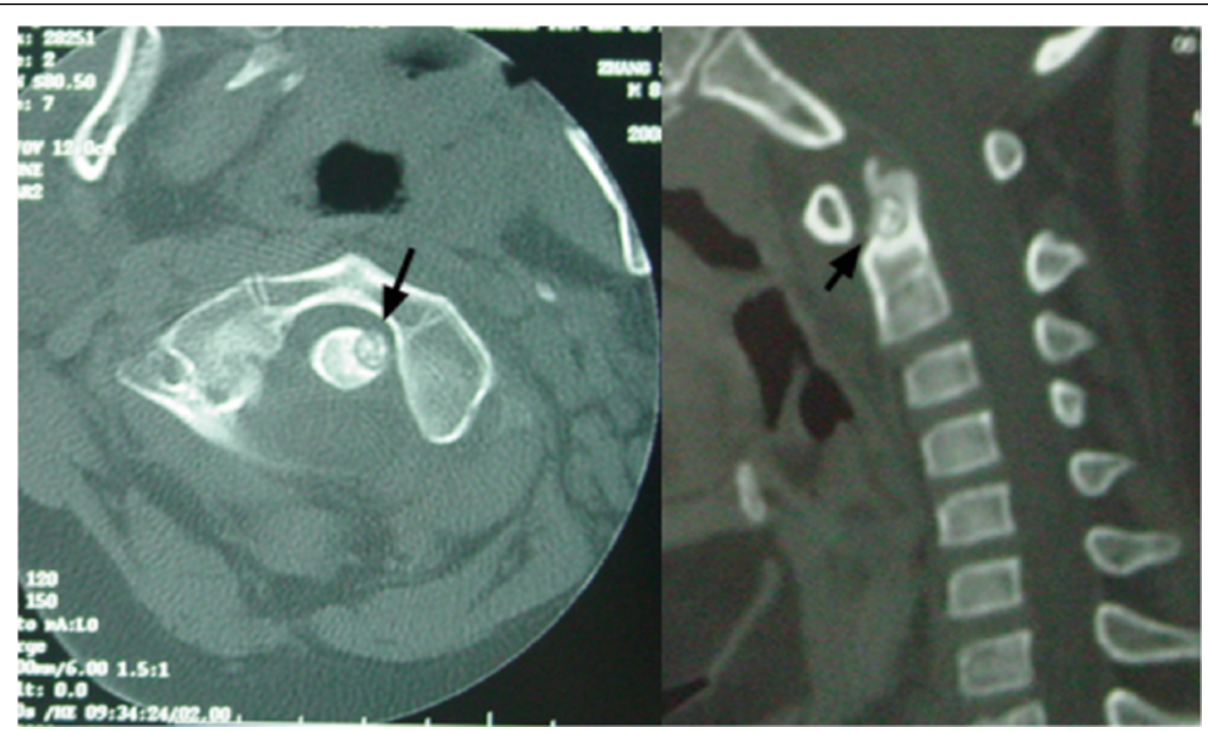

Figure 2 Transversal computed tomography (CT) images showing the nidus with partial ossification of matrix and sclerotic margin, and sagittal CT images of the nidus. 


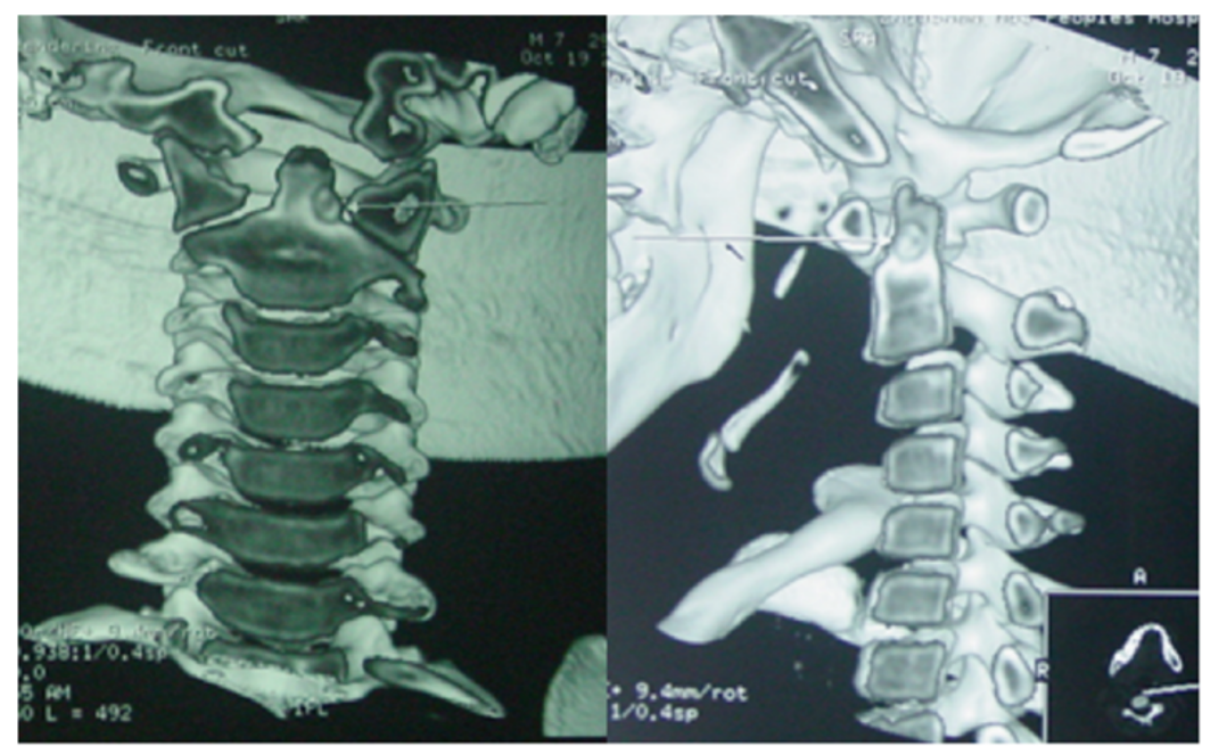

Figure 3 Computed tomography (CT) of three-dimensional (3-D) reconstruction of the nidus.

paraganglioma, plasmacytoma, multiple myeloma and so on [22]. Osteoblastoma is the major differential diagnosis of osteoid osteoma because they have the same pathological features but distinct natures. In contrast to osteoid osteoma, osteoblastoma is more aggressive, often extending to extraskeletal soft tissues. Moreover, it often recurs and even metastasizes after surgery [23-25]. In pathology, the two tumors are both lesions of osteoblastic origin $[7,26]$. The most significant difference between them is the size of the nidus. A lesion is diagnosed as osteoid osteoma when its diameter is less than $15 \mathrm{~mm}$ and as osteoblastoma when larger [27].

Surgeons often hold progressive attitudes toward the treatment of osteoid osteoma. For example, en block excision is frequently recommended [28,29]. In addition, minimally invasive methods, such as CT-guided thermocoagulation and percutaneous radiofrequecy ablation have also obtained satisfactory outcomes [30-32]. When the tumor is combined with scoliosis, surgical excision with or without correction surgery is widely adopted. However, surgical treatment is by no means the only choice, and surgeons should weigh costs against benefits before a decision is made. In the present case, conservative treatment was administered in consideration of economic issues and surgical risks. In developing countries, the coverage of medical insurance is inadequate, and many patients cannot afford surgical expenses. For this kind of benign tumor, conservative treatment plus close follow-up is applicable. Moreover, the risky anatomic location of the lesion and the high morbidity further prompted us to choose medication, with a satisfactory outcome [13,33].

\section{Conclusions}

For this kind of benign tumor, conservative treatment plus close follow-up is applicable whereas surgery bears significant risks and a heavy economic burden.

\section{Consent}

Written informed consent was obtained from all patients enrolled in the investigation. The study protocol conformed to the ethical guidelines of the 1975 Declaration of Helsinki and the guidelines of the regional ethical committees of Zurich, Switzerland, and Basel, Switzerland.

\section{Abbreviations}

CT: computed tomography; MRI: magnetic resonance imaging; NSAIDs: non-steroidal anti-inflammatory drugs.

\section{Competing interests}

The authors declare that they have no competing interests.

\section{Authors' contributions}

$J Q$ and $Y Q$ conceived the study and design. JQ, FZ, ZZ, ZL and BQ undertook acquisition of data. JQ analyzed and interpreted the data and drafted the manuscript. FZ, ZZ, and YQ performed critical revision of the manuscript. QY supervised the study. All authors read and approved the final manuscript.

\section{Acknowledgements}

This work was supported by National Key Clinical Department Project and Talents Programme of Jiangsu (Grant No. WSW-005). We thank MS Zhang Linlin for her contribution to this article.

Received: 15 February 2014 Accepted: 25 September 2014 Published: 6 October 2014

\section{References}

1. Jaffe HL: Osteoid osteoma: a benign osteoblastic tumor composed of osteoid and atypical bone. Arch Surg 1935, 31:709-715.

2. Kirman EO, Hutton PA, Pozo JL, Ransford AO: Osteoid-osteoma and benign osteoblastoma of the spine. J Bone Joint Surg (Br) 1984, 66:21-26. 
3. Pettine KA, Klassen RA: Osteoid-osteoma and osteoblastoma of the spine. J Bone Joint Surg Am 1986, 68:354-360.

4. Jaffe HL: Benign osteoblastoma. Bull Hosp Joint Dis 1956, 17:141-151.

5. Hurtgen $\mathrm{KL}$, Buehler M, Santolin SM: Osteoid osteoma of the vertebral body with extension across the intervertebral disc. J Manipulative Physiol Ther 1996, 19:118-122.

6. Resnick D, Kyriakos M, Greenway G: Tumors and tumor-like lesions of bone: Imaging and pathology of specific lesions. In Diagosis of Bone and Joint Disorders. 3rd edition. Edited by Resnick D. Philadelphia, PA: Saunders; 1995:3628-3657.

7. Zilieli M, Cagli S, Basdemir G, Ersahin Y: Osteoid osteomas and osteoblastomas of the spine. Neurosurg Focus 2003, 15:E5.

8. Al-Balas H, Omaeri H, Mustafa Z, Matalka I: Osteoid osteoma of the odontiod process of the axis associated with atlanto-axial fusion. $\mathrm{Br} J$ Radiol 2009, 82:e126-e128.

9. Neumann D, Dorn U: Osteoid osteoma of the dens axis. Eur Spine J 2007 16:271-274.

10. Hermann G, Abdelwahab IF, Casden A, Mosesson R, Klein MJ: Osteoid osteoma of a cervical vertebral body. Br J Radiol 1999, 72:1120-1123.

11. Greenspan A: Benign bone forming lesions: osteoma, osteoid osteoma, osteoblastoma. Clinical imaging, pathologic and differential considerations. Skel Radiol 1993, 22:485-500.

12. Hasegaga T, Hirose T, Sakamoto R, Seki K, Ikata T, Hizawa K: Mechannism of pain in osteoid ostomas: an immunohistochemical study. Histopathology 1993, 22:487-491.

13. Kneisl JS, Simon MA: Medical management compared with operative treatment for osteoid osteoma. J Bone Joint Surg Am 1992, 74:179-185.

14. Maiuri F, Signoreli C, Lavano A, Gambardella A, Simari R, D'Andrea F: Osteoid osteoma of the spine. Surg Neurol 1986, 25:375-380.

15. Metha MH: Pain provoked scoliosis: observations on the evolution of the deformity. Clin Orthop 1978, 135:58-65.

16. Saifuddin A, White J, Sherazi Z, Shaikh MI, Natali C, Ransford AO: Osteoid osteoma and osteoblastoma of the spine: Factors associated with the presence of scoliosis. Spine 1998, 23:47-53.

17. Gamba JL, Martinez S, Apple J, Harrelson JM, Nunley JA: Computed tomography of axial skeletal osteiod osteoma. AJR 1984, 142:769-772.

18. Kransdorf MJ, Stull MA, Gilkey FE, Moser RP Jr: Osteoid osteoma. RadioGraphic 1991, 11:671-696.

19. Houang B, Grenier N, Greselle JF: Osteoid osteoma of the cervical spine: misleading MR features about a case involving the uncinate process. Neuroradiology 1990, 31:541-551.

20. Woods ER, Martel W, Mandell SH, Crabbe JP: Reactive soft-tissue mass associated with osteoid osteoma : correlation of MR imaging features with pathologic findings. Radiology 1993, 186:221-225.

21. Assoun J, Richardi G, Railhac JJ, Crabbe JP: Osteoid osteoma: MR imaging versus CT. Radiology 1994, 191:217-223.

22. Piper JG, Menezes AH: Management strategies for tumors of the axis vertebra. J Neurosurg 1996, 84:543-551.

23. Bruneau M, Cornelius JF, George B: Osteoid osteomas and osteoblastomas of the occipitocervical junction. Spine 2005, 30:567-571.

24. Pieterse AS, Vernon-Roberts B, Paterson DC, Cornish BL, Lewis PR: Osteoid osteoma transforming to aggressive (low grade malignant) osteoblastoma: a case report and literature review. Histopathology 1983, 7:789-800.

25. Ozaki T, Liljenqvist U, Hillmann A, Halm H, Lindner N, Gosheger G, Winkelmann W: Osteoid osteoma and osteoblastoma of the spine: experiences with 22 patients. Clin Orthop 2002, 397:394-402.

26. De Praeter MP, Dua GF, Seynaeve PC, Vermeersch DG, Klaes RL: Occipital pain in osteoid osteoma of the atlas. A report of two cases. Spine 1999, 24:912-914.

27. Nemoto O, Moser RP Jr, Van Dam BE, Vermeersch DG, Klaes RL: Osteoblastoma of the spine. A review of 75 cases. Spine 1990, $15: 1271-1280$

28. Azouz EM, Kozlowski K, Marton D, Sprague P, Zerhouni A, Asselah F: Osteoid osteoma and osteoblastoma of the spine in children: Report of 22 cases with brief literature review. Pediatr Radiol 1986, 16:25-31.

29. Raskas DS, Graziano GP, Heidelberger KP, Heidelberger KP, Hensinger RN: Osteoid and osteoma of the spine. J Spinal Disord 1992, 5:204-211.
30. Cove JA, Taminiau AH, Obermann WR, Vanderschueren GM: Osteoid osteoma of the spine treanted with percutaneous computed tomography-guided thermocoagulation. Spine 2000, 25:1283-1286.

31. Rosenthal DI, Springfiled DS, Gebhardt MC, Rosenberg AE, Mankin HJ: Osteoid osteoma: percutaneous radio-frequency ablation. Radiology 1995, 197:451-454.

32. Vanderschueren GM, Taminiau AH, Obermann WR, Bloem JL: Osteoid osteoma: clinical results with thermocoagulation. Radiology 2002, 224:82-86.

33. Ilays I, Younge DA: Medical management of osteoid ostoma. Can J Surg 2002, 45:435-437.

doi:10.1186/1477-7819-12-305

Cite this article as: Qiao et al:: Conservative treatment for osteoid osteoma of the odontoid process of the axis: a case report. World Journal of Surgical Oncology 2014 12:305.

\section{Submit your next manuscript to BioMed Central and take full advantage of:}

- Convenient online submission

- Thorough peer review

- No space constraints or color figure charges

- Immediate publication on acceptance

- Inclusion in PubMed, CAS, Scopus and Google Scholar

- Research which is freely available for redistribution 